\title{
lon-association dispersive liquid-liquid microextraction of ultra-trace amount of gold in water samples using Aliquat 336 prior to inductively coupled plasma atomic emission spectrometry determination
}

\author{
Jalal Hassan ${ }^{{ }^{*}}$, Naeemeh Zari ${ }^{2}$, Kourosh Tabar-Heydar ${ }^{2}$ and Seyyed Hamid Ahmadi ${ }^{2}$
}

\begin{abstract}
Background: Gold is a rare and noble metal with atomic number of 79. Several techniques including both spectrometric and electrochemical methods are widely used to determine gold level in real samples. As a result of low concentration of gold in environmental samples, sample preparations such as extraction, clean-up, and pre-concentration before instrumental analysis are mandatory. Thus, a pre-treatment method (dispersive liquid-liquid microextraction (DLLME)) for gold pre-concentration and inductively coupled plasma optical emission spectrometry (ICP-OES) determination is proposed.

Methods: An extraction method employing DLLME and ICP-OES has been developed for rapid separation, pre-concentration, and determination of ultra-trace amount of $\mathrm{Au}$ (III). The extraction of the analyte was performed in the presence of a quaternary ammonium cation, $N$-methyl- $N, N, N$-trioctylammonium chloride, (Aliquat 336) as an extractant based on ion-association extraction system.

Results: 1-Octanol and acetonitrile were used as extraction and disperser solvents, respectively. The variables affecting the extraction conditions were optimized. A calibration curve in the range of $0.3-100 \mathrm{ng} \mathrm{mL}^{-1}$, the detection limit of $0.09 \mathrm{ng} \mathrm{mL}^{-1}$, an enrichment factor of 150 , and an extraction recovery of $74 \%$ were obtained. The precision (RSD \%) of the method was $6 \%$ for five replicates and recoveries of $10 \mathrm{ng} \mathrm{mL}^{-1} \mathrm{Au}(\mathrm{III})$.

Conclusions: The combined DLLME method with ICP-OES can readily determine Au(III) at trace $\left(\mu \mathrm{g} \mathrm{L}^{-1}\right)$ level using only $10 \mathrm{~mL}$ of sample solution (tap, lake, and mining water) without interference by the matrices. This methodology is simple, fast, and low cost which can be used in routine analytical laboratories.
\end{abstract}

Keywords: Gold, Dispersive liquid-liquid microextraction, Aliquat 336, Inductively coupled plasma atomic emission spectrometry

\footnotetext{
* Correspondence: jalalhassan1355@yahoo.com

1Division of Toxicology, Department of Basic Sciences, Faculty of Veterinary

Medicine, University of Tehran, Tehran, Iran

Full list of author information is available at the end of the article
} 


\section{Background}

Gold is a rare and noble metal with atomic number of 79 and 14 radioactive isotopes with half-times from a few seconds to a few days (Aitio et al. 2014). The word noble refers in part to its rarity, beauty, and wide utility in economic and industrial activity due to its chemical stability, high ductility, corrosive resistance, and low impedance (Kagaya et al. 2010). The average concentration of gold in earth's crust is approximately $4 \mu \mathrm{g} \mathrm{kg}^{-1}$ (ppb) and the values of 0.05 and $0.2 \mathrm{ng} \mathrm{mL}{ }^{-1}$ (ppb) were found in sea water and river water, respectively (Lee 1996; Rancis et al. 2005). Several techniques including both spectrometric and electrochemical methods are widely used to determine gold in real samples (Shamsipour and Ramezani 2008; Gomez and McLeod 1993; Ye and Beng khoo 1999; $\mathrm{Hu}$ et al. 2006; de-Souza Periera et al. 2014; Ye et al. 2014). As a result of a low concentration of gold in environmental samples and matrix interferences, the limiting factor in the analysis is often the sensitivity of the method. Therefore, sample preparations such as extraction, cleanup and pre-concentration before instrumental analysis are mandatory. Solid-phase extraction (Zhang et al. 2011; Sabermahani et al. 2012; Iraji et al. 2013; Afzali et al. 2014; Kazemi et al. 2015), cloud-point extraction (Manzoori et al. 2007; Tavakoli et al. 2008), co-precipitation (Messerschmidt et al. 2000), and liquid-liquid extraction (LLE) (ElShahawi et al. 2007; Vasilyeva et al. 1975; Ohava et al. 1995; Kolekar and Anuse 2001) are used for sample preparation purposes. LLE has been widely used for separation and pre-concentration of gold ions. This technique is based on transfer of desired analytes from the primary aqueous sample to water-immiscible solvent (Pena-Periera et al. 2009). Gold ion normally exists in an aqueous phase as a hydrated anion complex $\left(\mathrm{AuCl}_{4}^{-}\right)$with little or no tendency to be transferred to organic phase. Suitable cations like quaternary ammonium cations (e.g., tetrabutylammonium), organometallic cations (e.g., $\mathrm{Ph}_{3} \mathrm{Sn}^{+}$), and cationic colorants (e.g., Rhodamine B) have been applied to form non-solvated ion-pair with $\mathrm{AuCl}_{4}^{-}$(Das and Bhatacharyya 1976) to produce extractable species. However, LLE is not without its associated problems such as being time consuming, large amount of toxic organic solvent consumption, and difficulty in automation. Recent trends in analytical chemistry are in the direction of simplification and miniaturization of sample preparation procedures as well as the minimization of solvent and reagent usage. So, dispersive liquid-liquid microextraction (DLLME) has been introduced for organic and inorganic analyte separation from aqueous matrices (Rezaee et al. 2006). DLLME is based on dispersion of extraction solvent in aqueous bulk samples assisted with a disperser solvent. Then, the analytes are allowed to be extracted into fine droplets of extraction solvent during the formation of cloudy solution (Anthemidis and Ionnp 2009). After centrifuging, the separated organic phase will be analyzed with appropriate techniques. The advantages of this technique include simplicity of operation, rapid extraction, and high-enrichment factors $\left(E_{f}\right)$ (Leong et al. 2014). DLLME studies related to ion metals involve the use of complexing reagents, ligandless-dispersive liquid-liquid microextraction (LLDLLME), and ion-pair forming agents. The two first approaches are widely used for different kinds of metals such as Pd (Mohammadi et al. 2010), Ag (Mohammadi et al. 2009a), and $\mathrm{Cu}$ (Mohammadi et al. 2009b) in the cationic form. The ion-pair-based approach has only been applied for gold following the formation of an ion-pair between $\mathrm{AuCl}_{4}^{-}$complex and different counterions such as Victoria Blue $\mathrm{R}$, dicyclohexylamine, benzyldimethyl tetradecyl ammonium, and between $\mathrm{AuCN}_{2}^{-}$complex and Astra Phloxin (De La Calle et al. 2011; Kocuroua et al. 2010).

Because of high toxicity and limitation in extracting various analytes of commonly used extraction solvents, two different aspects (I) the use of new solvents, typically ionic liquids and (II) the expansion of the application scope using polar and low-density organic solvents such as long-chained alcohols or hydrocarbons are considered (Yana and Wanga 2013). In this study, a pretreatment method (DLLME) for Au determination with a quaternary ammonium salt, $N$-methyl- $N, N, N$-trioctylammonium chloride, (Aliquat 336) as an extractant reagent based on ion-association solvent extraction system is proposed. The purpose of the present work is to optimize various parameters affecting the efficiency of the combination of microextraction and ICP-OES for the determination of gold in water samples.

\section{Methods}

\section{Reagents and solutions}

Reagent grade 1-octanol, 1-dodecanol, acetonitrile, acetone, ethanol, $\mathrm{NaCl}, \mathrm{HCl}$, and $\mathrm{HNO}_{3}$ were purchased from Merck chemical company (Darmstadt, Germany) and $N$ methyl- $N, N, N$-trioctylammonium chloride (Aliquat 336) was purchased from Sigma-Aldrich (USA). Doubly distilled deionized water was prepared by MiliQ water (Merck, Millipore) and was used in all experiments. A stock standard solution of gold as $\mathrm{AuCl}_{4}^{-}$and other trace and major elements (for interfering studies) $(1000 \mu \mathrm{g} \mathrm{mL}$

${ }^{-1}$-SM 80B-500 VHG Labs-USA) were utilized and diluted to the desired concentration daily prior to use. Tap water (Karaj, Alborz province, Iran), lake water (Orumieh, West Azarbaijan, Iran), and mining water (Anguran mine, Zandjan province, Iran) samples were collected in acidleached polyethylene bottles and acidified by $\mathrm{HNO}_{3}$.

\section{Instrumentation}

In this study, a simultaneous radial viewing torch configuration ICP-OES (Varian 735-OES, Australia) equipped 
with charge-coupled device (CCD) detector has been used for the determination of gold. The control of the spectrometer is provided by PC-based ICP Expert II software. All measurements were carried out in timescan mode at $242.8 \mathrm{~nm}$ ionic emission Au spectrum. A Vision VS $5500 \mathrm{~N}$ Centrifuge (Korea) was used to speed up the phase separation.

\section{General procedure}

In a $10-\mathrm{mL}$ volumetric flask, $3.5 \mathrm{~mL}$ concentrated $\mathrm{HCl}$, $2.0 \mathrm{~mL} \mathrm{AuCl}_{4}^{-}$solution $\left(1.0 \mathrm{mg} \mathrm{L}^{-1}\right)$, and $0.5 \mathrm{~g} \mathrm{NaCl}$, salt were added and diluted to the mark with distilled water and transferred to a proper homemade test tube (final concentration of gold was $0.200 \mathrm{mg} \mathrm{L}^{-1}$ ). Fifty microliters of 1-octanol as extraction solvent containing Aliquat $336(0.1 \% w / v)$ and $1.5 \mathrm{~mL}$ acetonitrile as disperser agent was together rapidly injected to test solution by a disposable syringe. A cloudy solution (water/1-octanolAliquat 336/acetonitrile) was formed in the test tube where the $\mathrm{AuCl}_{4}^{-}$is extracted into fine droplet of 1octanol by aid of Aliquat 336 as an ion-association agent. The mixture was then centrifuged for $10 \mathrm{~min}$ at $2900 \mathrm{rpm}$. After this process, the dispersed fine droplets were collected on the top of the solution in the neck of the homemade test tube. Finally, the collected organic phase $(50 \pm 3 \%(\mu \mathrm{L}))$ was introduced to ICP-OES instrument through four-channel peristaltic pump, and the gold content was determined in time-scan mode. When running organic samples by ICP-OES, a higher power level $(1.6 \mathrm{KW})$ and lower nebulizer flow rate $\left(0.6 \mathrm{~L} \mathrm{~min}^{-1}\right)$ are required to ignite and maintain plasma. With correctly chosen conditions, the intense green tongue generated by molecular emission of $\mathrm{C} 2$ and $\mathrm{CN}$ emission will be visible between the turns of the induction coil but will not extend above the top of the torch (Boorn and Browner 1982). So, the viewing height in this study was chosen $15 \mathrm{~mm}$ above the load coil to avoid background emission due to green tongue.

\section{Preparation of water samples}

Tap water sample from laboratory of applied geological research center of GSI (Karaj, Alborz province), Lake water as a source for hydro-geochemistry studies from Orumieh lake (Orumieh, West Azarbaijan province), and mining water from Anguran mine (Zandjan province) were collected in acid-leached poly(ethylene) bottles, filtered, and acidified with $\mathrm{HNO}_{3}$ to prevent adsorption of metal ions on the bottle wall.

\section{Preparation of certified reference material (CRM) samples} The proposed method was also applied to the extraction and determination of gold in three geochemical reference samples (GAU 15-17). An accurately measured sample $(0.5000 \mathrm{~g})$ of GAUs was dissolved in aqua regia. The solution was evaporated to near dryness to remove the nitrogen oxides. Then, $10 \mathrm{~mL}$ distilled water and a few drops of concentrated hydrochloric acid were added. The solution was filtered, and the filtrate was transferred completely into a calibrated $25-\mathrm{mL}$ volumetric flask and diluted to the mark with water. The extraction and determination of gold content was carried out following the general procedure described.

\section{Results and discussion}

In order to achieve the optimized experimental conditions for high-enrichment factor and quantitative extraction of gold ions by Aliquat 336 through ionassociation DLLME, the influence of some important parameters including concentration of ion-association agent (Aliquat 336), $\mathrm{HCl}$ concentration, salt concentration, and nature and volume of both extraction and disperser solvents were investigated. These surveys were done due to their effects on emission signal of gold extracted to organic phase. In general, the enrichment factor $\left(E_{f}\right)$, extraction recovery $\left(E_{r}\right)$ can be defined as following equations:

OCTANOL PHASE
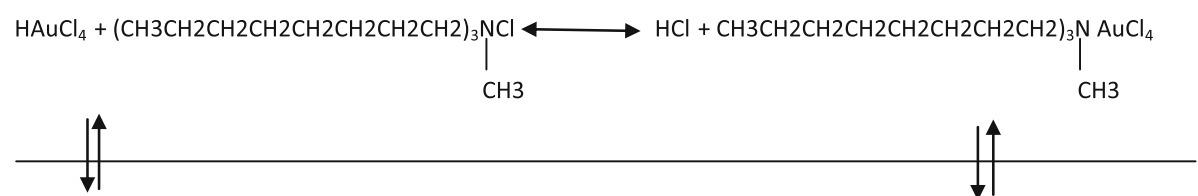

$\mathrm{HAuCl}_{4}$

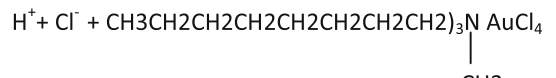

$\mathrm{CH} 3$ 


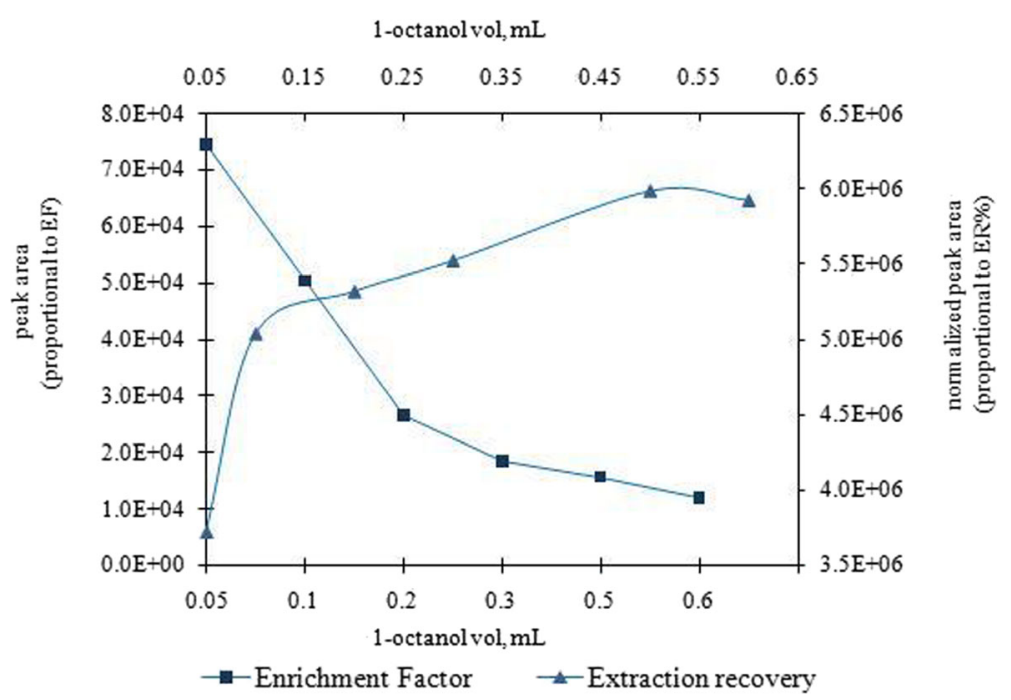

Fig. 1 The effect of the amount of extraction solvents on extracted Au(III) signals. Extraction conditions: sample solution, $10 \mathrm{~mL}$ of gold (200 $\left.\mu \mathrm{g} \mathrm{L}{ }^{-1}\right)$; extraction solvent, 1-octanol containing Aliquat $336(5 \% \mathrm{w} / \mathrm{v})$; $\mathrm{HCl}$ concentration $\left(2 \mathrm{~mol} \mathrm{\textrm {L } ^ { - 1 }}\right)$; disperser solvent $1.5 \mathrm{~mL}$ acetone

$$
\begin{aligned}
& E_{f}=\frac{C_{\mathrm{eq}}^{e}}{C_{\mathrm{ini}}^{s}} \\
& E_{r}=\frac{n_{\mathrm{ex}}}{n_{\mathrm{ini}}}=\frac{C_{\mathrm{eq}}^{\mathrm{ex}} V_{\mathrm{ex}}}{C_{\mathrm{ini}}^{\mathrm{sam}} V_{\mathrm{sam}}}
\end{aligned}
$$

where $C_{\mathrm{eq}}^{o}$ is the final concentration of analyte in the organic phase, $C_{\text {ini }}^{s}$ is the initial analyte concentration in the sample phase, $n_{\mathrm{ex}}$ is the moles of the analyte extracted into the extracting phase and $n_{\mathrm{ini}}$ is the total moles of the analyte, and $V_{\text {ex }}$ and $V_{\text {sam }}$ are the final (separated) volume of extracting phase and initial volume of

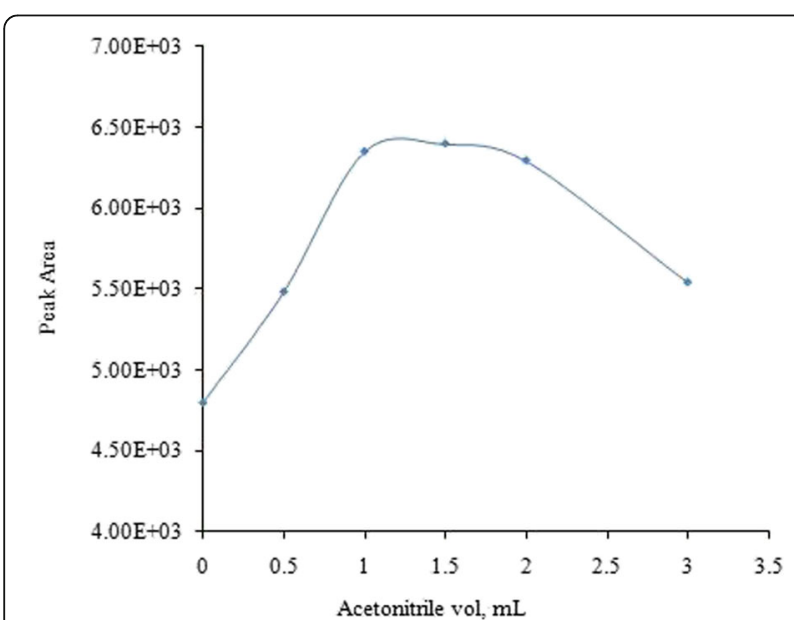

Fig. 2 The effect of the volume of disperser solvents on extracted $\mathrm{Au}(\mathrm{III})$ signals. Extraction conditions: sample solution, $10 \mathrm{ml}$ of gold (200 $\mathrm{g} \mathrm{L} \mathrm{L}^{-1}$ ); extraction solvent, 1-octanol containing Aliquat 336 $(5 \% \mathrm{~W} / \mathrm{v}) ; \mathrm{HCl}$ concentration $\left(2 \mathrm{~mol} \mathrm{~L}^{-1}\right)$; disperser solvent acetonitrile sample, respectively. As the nature of organic solvent can improve emission signal, enhancement factor can be obtained by division of slope of the calibration curve related to LLE procedure to that of aqueous solution.

$$
E_{n}=\frac{\text { LLE-calibration-slope }}{\text { Aqueous-calibration-slope }}
$$

$E_{f}$ can be also defined as the slope of the calibration curve related to DLLME procedure to that of DLLME procedure (Shamsipour and Ramezani 2008) (Scheme 1).

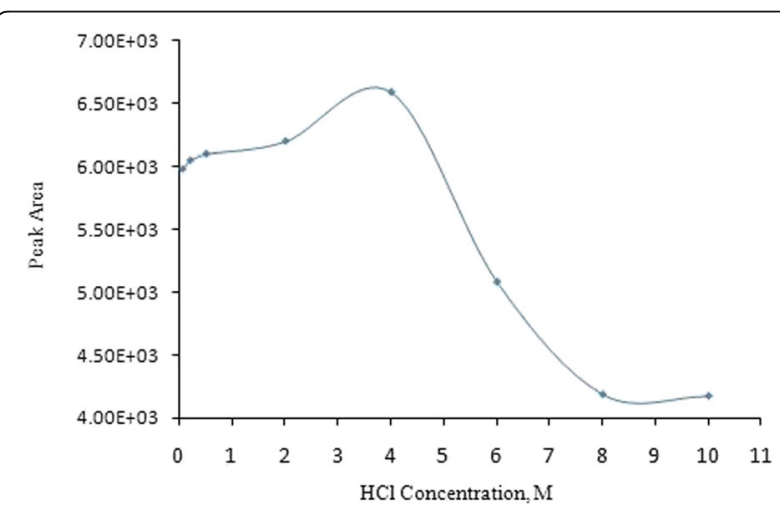

Fig. 3 The effect of $\mathrm{HCl}$ concentration on extracted $\mathrm{Au}(\mathrm{III})$ signals. Extraction conditions: sample solution, $10 \mathrm{~mL}$ of gold $\left(200 \mathrm{\mu g} \mathrm{L}^{-1}\right)$; extraction solvent, $350 \mu \mathrm{L}$ 1-octanol containing Aliquat $336(5 \% \mathrm{~W} / \mathrm{V})$; disperser solvent $1.5 \mathrm{~mL}$ acetonitrile 


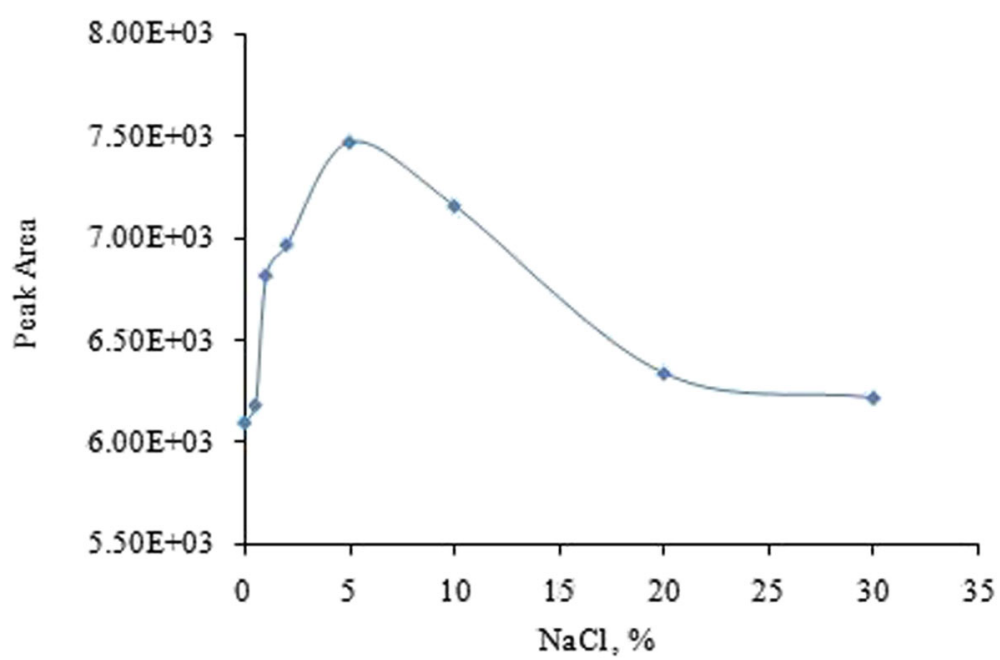

Fig. 4 The effect of salt concentration on extracted $\mathrm{Au}\left(\right.$ (III) signals. Extraction conditions: sample solution, $10 \mathrm{~mL}$ of gold $\left(200 \mu \mathrm{g} \mathrm{L}{ }^{-1}\right)$; extraction solvent, $350 \mu \mathrm{L}$ 1-octanol containing Aliquat $336(5 \% \mathrm{~W} / \mathrm{v})$; $\mathrm{HCl}$ concentration $\left(2 \mathrm{~mol} \mathrm{~L}^{-1}\right)$; disperser solvent $1.5 \mathrm{~mL}$ acetonitrile

$$
E_{f}=\frac{\text { DLLME-calibration-slope }}{\text { Aqueous-calibration-slope }}
$$

\section{Nature and amount of extraction solvent}

Extraction solvent plays a prominent role in a successful extraction procedure (Rezaee et al. 2010). In general, the extraction solvent must be able to extract the analyte well and has low solubility in aqueous medium. Highdensity extraction solvents, being mostly halogenated, are generally toxic and have high background emission in ICP-OES, accordingly alcohols with lower densities than aqueous solutions and less volatile were chosen in this test. The solvents that were tested in this work are 1-octanol and 1-dodecanol (due to their compatibility with ICP-OES). The results showed that the organic phase after extraction by 1-octanol had higher overall extraction recovery for the target analyte than 1dodecanol. Therefore, 1-octanol was selected for further studies.

In order to evaluate the effect of extraction solvent volume, different volumes of 1-octanol (i.e., 50 to $600 \mu \mathrm{L}$ ) were examined with the same DLLME procedure. The collected organic phase diluted to $700 \mu \mathrm{L}$ with 1 -octanol and introduced to ICP-OES. The resulting curves of the peak area, obtained by time-scan mode, against the volume of extraction solvent are shown in Fig. 1.

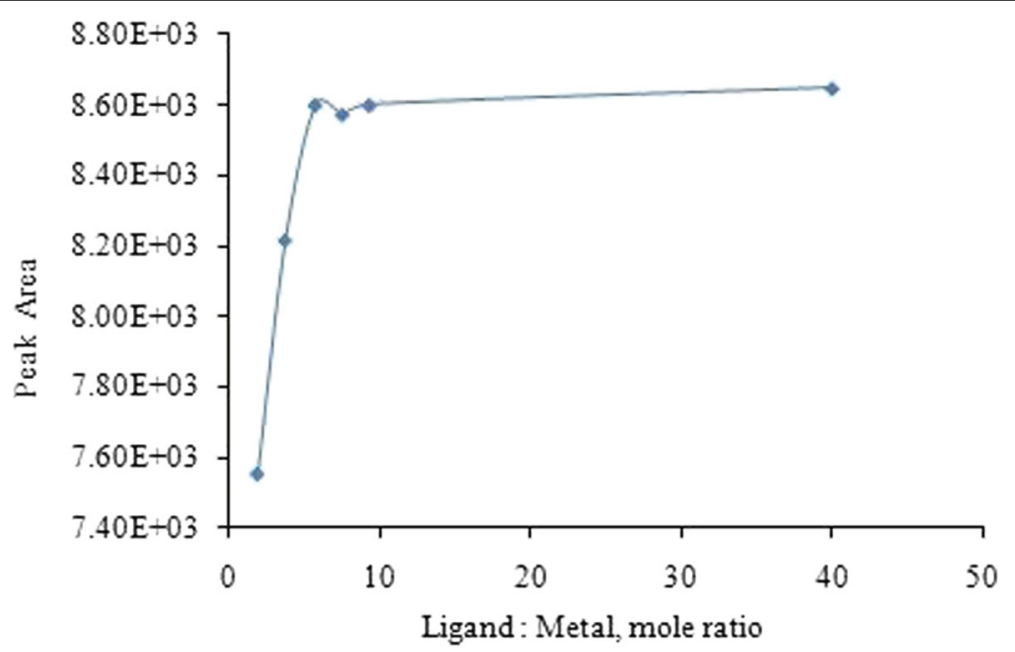

Fig. 5 The effect of the amount of ion-association reagent on extracted Au(III) signals. Extraction conditions: sample solution, $10 \mathrm{~mL}$ of gold $\left(200 \mu \mathrm{g} \mathrm{L}^{-1}\right)$; extraction solvent, $350 \mu \mathrm{L}$ 1-octanol containing Aliquat $336(5 \% \mathrm{~W} / \mathrm{v})$; $\mathrm{HCl}$ concentration $\left(2 \mathrm{~mol} \mathrm{~L}^{-1}\right)$; disperser solvent $1.5 \mathrm{~mL}$ acetonitrile 
The results showed that the peak area (proportional to concentration) of the extracted gold decreased with the increasing volume of 1-octanol in the studied range. However, as expected, the normalized peak area (extraction recovery) increased with the increasing volume of 1-octanol. For trace analysis, high-enrichment factor is more critical than extraction efficiency, so $50 \mu \mathrm{L}$ of solvent was chosen as the optimized volume for analysis.

\section{Type and amount of disperser solvent}

The disperser solvent has to be highly miscible with both water and the extraction solvent. Disperser solvent has an important effect on decreasing the interfacial tension between water and extracting solvent and thus makes the droplet size smaller. Thereby, acetone, ethanol, and acetonitrile which have these properties were tested as disperser solvents in this work. Acetonitrile was chosen as disperser solvent due to its highest emission intensity of extracted phase containing target $\mathrm{Au}(\mathrm{III})$.

Since the variation in volume of acetonitrile caused a change in emission intensity of extracted $\mathrm{AuCl}_{4}^{-}$, it was necessary to optimize the volume of disperser solvent. It was found that at low volume of acetonitrile, the cloudy solution was not completely formed whereas at high acetonitrile volume, there was completely one phase; therefore, it was important to optimize the volume of acetonitrile. The test was done with $10 \mathrm{~mL}$ of $\mathrm{Au}(\mathrm{III})$ (200 $\left.\mu \mathrm{g} \mathrm{L}^{-1}\right)$ with varying volumes $(0.1,0.5,1,2,4$,

Table 1 The effect of foreign ions on pre-concentration and determination of $\mathrm{Au}(\mathrm{III})\left(20 \mu \mathrm{g} \mathrm{L^{-1 }}\right)$

\begin{tabular}{lll}
\hline lons & Ion/Au ratio & Extraction recovery (\%) \\
\hline $\mathrm{Cr}$ & 500 & $96 \pm 6$ \\
$\mathrm{Co}$ & 100 & $96 \pm 6$ \\
$\mathrm{Cd}$ & 500 & $96 \pm 6$ \\
$\mathrm{Ni}$ & 500 & $96 \pm 6$ \\
$\mathrm{Mn}$ & 500 & $104 \pm 6$ \\
$\mathrm{~Pb}$ & 500 & $95 \pm 6$ \\
$\mathrm{SC}$ & 100 & $96 \pm 6$ \\
$\mathrm{Zn}$ & 500 & $96 \pm 6$ \\
$\mathrm{Ba}$ & 100 & $96 \pm 6$ \\
$\mathrm{Mg}$ & 1000 & $95 \pm 6$ \\
$\mathrm{Al}$ & 2000 & $101 \pm 6$ \\
$\mathrm{Ca}$ & 2000 & $96 \pm 6$ \\
$\mathrm{Na}$ & 2000 & $95 \pm 6$ \\
$\mathrm{Fe}$ & 2000 & $101 \pm 6$ \\
$\mathrm{~K}$ & 1000 & $98 \pm 6$ \\
$\mathrm{Pd}$ & 500 & $107 \pm 6$ \\
$\mathrm{Pt}$ & 500 & $107 \pm 6$ \\
$\mathrm{Ir}$ & 100 & $105 \pm 6$ \\
\hline
\end{tabular}

Table 2 Determination of $A u(I I)$ in water samples

\begin{tabular}{llll}
\hline Samples & $\begin{array}{l}\text { Added } \\
\left(\mu \mathrm{L} \mathrm{L}^{-1}\right)\end{array}$ & $\begin{array}{l}\text { Found value } \\
\left(\mu \mathrm{g} \mathrm{L}^{-1}\right)\end{array}$ & Recovery (\%) \\
\hline Anguran mine drainage & - & $<\mathrm{LOD}$ & - \\
Urumieh Lake & 10.0 & $9.9 \pm 1.4$ & $99 \pm 15$ \\
& - & $<\mathrm{LOD}$ & - \\
Tap water & 10.0 & $10.6 \pm 0.7$ & $106 \pm 7$ \\
& - & $<\mathrm{LOD}$ & - \\
\hline
\end{tabular}

$5 \mathrm{~mL}$ ) of acetonitrile and the results are shown in Fig. 2. As seen, the emission signal of extracted phase increases with the increasing volume of acetonitrile up to $1.5 \mathrm{~mL}$ and decreases by increasing the acetonitrile volume.

\section{Effect of $\mathrm{HCl}$ concentration}

The concentration of $\mathrm{HCl}$ is one of the most important parameters that affect the formation of $\mathrm{AuCl}_{4}^{-}$...Aliquat 336 ion-association compound and its extraction. Thus, the influence of $\mathrm{HCl}$ concentration (in the range of $0.1-$ $10 \mathrm{~mol} \mathrm{~L}^{-1}$ ) on the extraction of $200 \mu \mathrm{g} \mathrm{L} \mathrm{L}^{-1}$ of $\mathrm{Au}(\mathrm{III})$ from $10 \mathrm{~mL}$ aqueous solution by the proposed method was studied. According to the obtained results, the emission signal was increased by increasing the $\mathrm{HCl}$ concentration up to $4 \mathrm{~mol} \mathrm{~L}^{-1}$ and start being lessened (Fig. 3). Thereby, $4 \mathrm{~mol} \mathrm{~L}^{-1}$ concentration of $\mathrm{HCl}$ for quantitative extraction of $\mathrm{Au}(\mathrm{III})$ was selected.

\section{Effect of salt concentration}

The influence of the ionic strength on the solution was evaluated by adding different amounts of $\mathrm{NaCl}$ up to saturation into the sample solution. The results (Fig. 4) showed that the ionic strength had an obvious effect on emission intensity of extracted $\mathrm{AuCl}_{4}^{-}$. By increasing the salt amount in solution up to $5 \%$, the extracted $\mathrm{Au}(\mathrm{III})$ signals increased, then a decrease in signal was seen.

\section{Amount of ion transfer reagent}

The influence of different amount of Aliquat 336 on the extraction efficiency was investigated as the mole ratio of reagent to metal, varying from 1.9 to 40 . The results showed that the extracted $\mathrm{Au}(\mathrm{III})$ signals sharply increased up to 5.7 mole ratio of the reagent to metal and then remained almost constant. As can be seen from Fig. 5, the optimum amount of the reagent was at the

Table 3 Determination of $A u(I I)$ in geochemical reference samples

\begin{tabular}{lccl}
\hline Sample & Certified $\left(\mu \mathrm{g} \mathrm{g}^{-1}\right)$ & Found $\left(\mathrm{\mu g} \mathrm{g}^{-1}\right)$ & Recovery \% \\
\hline GAU 15 & $0.30 \pm 0.01$ & 0.27 & 90 \\
GAU 16 & $1.09 \pm 0.04$ & 1.0 & 91 \\
GAU 17 & $3.14 \pm 0.08$ & 2.9 & 94 \\
\hline
\end{tabular}


Table 4 Comparison of different method for determination of gold in aqueous samples

\begin{tabular}{llllll}
\hline Method & EF & LOD $\left(\mu \mathrm{g} \mathrm{L}^{-1}\right)$ & RSD $(\%)$ & Linear range $\left(\mu \mathrm{g} \mathrm{L}^{-1}\right)$ & Ref \\
\hline DLLME-GFAAS & 388 & 0.005 & 4.2 & $0.03-0.5$ & Shamsipour and Ramezani 2008 \\
SPE-FAAS & - & 0.8 & 1.7 & $50-34000$ & Sabermahani et al. 2012 \\
CPE-ICP-OES & 8.6 & 0.5 & $<5$ & $0.5-1000$ & Tavakoli et al. 2008 \\
SPE-ICP-OES & 150 & 0.32 & 3.3 & - & Zhang et al. 2011 \\
UAE-DLLME-ETAAS & 220 & 0.008 & 4.2 & $0.075-0.75$ & Mohammadi et al. 2010 \\
USAE-SFODMS-FAAS & 34.8 & 0.45 & 1.68 & $1.5-400$ & Tajic and Taher 2011 \\
DLLME-ICP-OES & 149 & 0.09 & 6 & $0.3-100$ & This work
\end{tabular}

DLLME Dispersive liquid-liquid microextraction, SPE Solid-phase extraction, UAE Ultrasound-assisted emulsification, USAE-SFODMS ultrasound-assisted emulsification of solidified floating organic drops, CPE Cloud point extraction

mole ratio of 5.7 and this amount of the reagent solution was used to be optimum in the subsequent experiment.

\section{Effect of foreign ions}

The effect of various ions on the efficiency of the method was studied under the optimized conditions. In order to demonstrate the selectivity of the proposed method, the recovery of Au from the sample solution in the presence of various interfering ions which are reported to be usually present in different gold real sample (Hassani Pak 2002) was investigated according to the recommended procedure. A relative error of 5\% was considered tolerable. The summarized results in Table 1 showed that these metal ions did not show any interfering effect at their studied levels for the determination of gold in various samples.

\section{Calibration graph and real sample}

The analytical characteristics of the proposed method were constructed under optimized conditions. These quantitative parameters were calculated using the values of the signals for analytical curve. The equation of linear calibration graph after pre-concentration procedure was $y=43.5 x-10.8$ with a regression coefficient better than 0.993 where $y$ is the emission signal of the considered element and gold concentration $(x)$ is expressed in $\mu \mathrm{g} \mathrm{L}$ ${ }^{-1}$. The limit of detection and quantification for gold, calculated according to $3 \mathrm{~S} / \mathrm{m}$ and $10 \mathrm{~S} / \mathrm{m}$ criteria (being $S$ the standard deviation of 8 consecutive blanks and $m$ the slope of calibration graph), were 0.09 and $0.32 \mu \mathrm{g} \mathrm{L}$ ${ }^{-1}$, respectively. The precision of the method was found to be $6 \%$ as the relative standard deviation of five replicates and recoveries of $10 \mu \mathrm{g} \mathrm{L}^{-1} \mathrm{Au}(\mathrm{III})$ from $10 \mathrm{~mL}$ aqueous solution. The enrichment factor for the proposed method defined as the slope of calibration curves with and without pre-concentration was found to be 150. The suggested procedure was applied to determine $\mathrm{Au}(\mathrm{III})$ in different water samples. When no aqueous standard reference materials with a certified content of target analyte are available, an add-found method can be considered as an alternative for validation studies
(Yamini et al. 2012). Tap, lake, and mine water samples were collected in acid-leached polyethylene bottles, and the results are summarized in Table 2. The accuracy of the method was further verified by the determination of the amount of gold ions in some geological reference samples (GAU 15-17) (Table 3). As it is obvious, the extraction efficiency was excellent and showed no serious matrix effects.

\section{Comparison with other methodologies}

As shown in Table 4, the main analytical characteristics of the present method for $\mathrm{Au}(\mathrm{III})$ pre-concentration/determination are compared with those of some of the previously reported methods in the literature. As can be seen, the proposed procedure shows good detection limit, wide linear dynamic range, and good enrichment factor comparable with several reported methods.

\section{Conclusions}

$\mathrm{Au}(\mathrm{III})$ can be selectively extracted from a sample solution in $\mathrm{HCl}\left(4 \mathrm{~mol} \mathrm{~L}^{-1}\right)$ media at the presence of other elements such as $\mathrm{Cr}, \mathrm{Co}, \mathrm{Pt}$, and $\mathrm{Pd}$. The combined DLLME method with ICP-OES can readily determine $\mathrm{Au}(\mathrm{III})$ at $\mu \mathrm{g} \mathrm{L}^{-1}$ level using only $10 \mathrm{~mL}$ of sample solution without interference by the matrices. In this method, using toxic-chlorinated solvents that are commonly used as extraction solvents is avoided. As the solvent and circumstances are compatible with ICPOES, there is no need to evaporate solvent for elemental analysis. This methodology is a simple, fast, green, and low cost which can be used with ICP-OES technique so could be of great interest for $\mathrm{Au}(\mathrm{III})$ determination in routine analytical laboratories.

\section{Acknowledgements}

This work has been supported by the Chemistry and Chemical Engineering Research Center of Iran and Applied Geological Research center of Geological Survey of Iran.

Authors' contributions

All authors read and approved the final manuscript. 


\section{Competing interests}

The authors declare that they have no competing interests.

\section{Author details}

'Division of Toxicology, Department of Basic Sciences, Faculty of Veterinary Medicine, University of Tehran, Tehran, Iran. ${ }^{2}$ Environmental Chemistry and Green Technology Department, Chemistry and Chemical Engineering Research Center of Iran, P.O. Box 14335-186, Tehran, Iran.

Received: 5 April 2016 Accepted: 20 October 2016

Published online: 05 November 2016

\section{References}

Afzali D, Daliri Z, Taher MA. Flame atomic absorption spectrometry determination of trace amount of gold after separation and preconcentration onto ionexchange polyethylenimine coated on Al2O3. Arab J Chem. 2014;7:770-4

Aitio A, Kiilunen M, Santonen T, Nordberg M, (2014) Handbook on the toxicology of metals vol 2, chapter 38, p 817-843, 4th edition, ISBN: 978-0-444-594532,ed. Gunnar F. Nordberg, Bruce A. Fowler, Monica Nordberg.

Anthemidis AN, lonnp K-LG. Recent developments in homogeneous and dispersive liquid-liquid extraction for inorganic elements determination. A review. Talanta. 2009:80:413-21.

Boorn AW, Browner RF. Effects of organic solvents in inductively coupled plasma atomic emission spectrometry. Anal Chem. 1982:54:1402-10.

Das NR, Bhatacharyya SN. Solvent extraction of gold. Talanta. 1976;23:535-40.

De La Calle I, Pena-Pereira F, Cabaleiro N, Lvilla I, Bandicho C. Ion pair-based dispersive liquid-liquid microextraction for gold determination at ppb level in solid samples after ultrasound-assisted extraction and in waters by electrothermal-atomic absorption spectrometry. Talanta. 2011;84:109-15.

De Souza PC, Mantovano JL, Turci CC, De MM, Fereira E. Determination of gold in ore samples by energy dispersive $\mathrm{X}$-rayfluorescence after separation and preconcentration on polyurethane foam. Microchem J. 2014;115:121-5.

El-Shahawi MS, Bshammakh AS, Bahaffi SO. Chemical speciation and recovery of gold(I, III) from wastewater and silver by liquid-liquid extraction with the ionpair reagent amiloride mono hydrochloride and AAS determination. Talanta. 2007;72:1494-9.

Gomez MM, McLeod CW. Trace enrichment and determination of gold by flow injection inductively coupled plasma atomic emission spectrometry. J Anal At Spectrom. 1993:8:461-5.

Hassani Pak AA. Gold Exploration, ISSBN 964-03-4180-0. Tehran: University Press; 2002.

Hu $\mathrm{Q}$, Chen X, Yang X, Huang Z, Chen J, Yang G. Solid phase extraction and spectrophotometric determination of Au (III) with 5-(2-Hydroxy-5nitrophenylazo)-thiorhodanine. Anal Sci. 2006;22:627-30.

Iraji A, Afzali D, Mostafavi A. Separation for trace amounts of Au (III) ion using ion-pair dispersive liquid-liquid microextraction prior to flame atomic absorption spectrometry determination. Int J Environ Anal Chem. 2013;93(3):315-24.

Kagaya S, Takata D, Yoshimori T, Kanbara T, Tohda K. A sensitive and selective method for determination of $\mathrm{Au}$ (III) based on electrothermal atomic absorption spectrometry in combination with dispersive liquid-liquid microextraction using dicyclohexylamine. Talanta. 2010;80:1364-70.

Kazemi E, Dad Farnia S, Haji Sabani A. M. Dispersive solid phase microextraction with magnetic graphene oxide as the sorbent for separation and preconcentration of ultra-trace amounts of gold ions. Talanta. 2015. http://dx doi.org/10.1016/j.talanta.2015.04.024.

Kocuroua L, Balogh IS, Skrilikova J, Posta J, Andruch V. A novel approach in dispersive liquid-liquid microextraction based on the use of an auxiliary solvent for adjustment of density: UV-VIS spectrophotometric and graphite furnace atomic absorption spectrometric determination of gold based on ion pair formation. Talanta. 2010;82:1958-64.

Kolekar SS, Anuse MA. Rapid solvent extraction of Au (III) with high molecular weight amine from organic acid solution. Gold Bull. 2001;34(2):50-5.

Lee JD. Concise inorganic chemistry. 5th ed. London: ELBS with Chapman and Hall; 1996.

Leong M.I, Fush M.R, Huang S.D. Beyond dispersive liquid-liquid microextraction. J. Chromatogr A. 2013;1335:2-14

Manzoori JL, Abdolmohammad-Zade H, Amjadi M. Simplified cloud point extraction for the preconcentration of ultra-trace amounts of gold prior to determination by electrothermal atomic absorption spectrometry. Microchim Acta. 2007;159:71-8.
Messerschmidt J, Bohlen AV, Alt FR, Klocken Kamper R. Separation and enrichment of palladium and gold in biological and environmental samples, adpted to the determination by total reflection X-ray fluorescence. Analyst. 2000;125:397-9.

Mohammadi S, Afzali ZD, Taher MA, Baghelania YM. Ligandless dispersive liquidliquid microextraction for the separation of trace amounts of silver ions in water samples and flame atomic absorption spectrometry determination. Talanta. 2009a;80:875-9.

Mohammadi SZ, Afzali D, Baghelania YM. Ligandless-dispersive liquid-liquid microextraction of trace amount of copper ions. Anal Chim Acta. 2009b;653:173-7.

Mohammadi SZ, Afzali D, Taher MA, Baghelania YM. Determination of trace amounts of palladium by flame atomic absorption spectrometry after ligandless-dispersive liquid-liquid microextraction. Microchim Acta. 2010;168:123-8.

Ohava T, Matsumoto S, Yamamoto H, Shibata J, Baba Y. Extraction of Au(III), Pd (II), Pt (IV) and Rh(III) with N- benzyl Aniline and their stripping behavior. Solvent Extr Res Dev Jpn. 1995;3:213-22.

Pena- Periera F, Lavilla I, Bendico C. Miniaturization methods based on liquidliquid extraction and their application in inorganic ultratrace analysis and speciation. Spectrochim Acta B. 2009;64:1-15.

Rancis SM, NiKolic- Mandic SD, Mandic LM. Kinetic spectrophotometric method for Au (III) determination. Anal Chim Acta. 2005;547:144-9.

Rezaee M, Asadi Y, Hosseini MR, Aghaee M, Fardin Ahmadi E, Sana Berijani S. Determination of organic compounds in water using dispersive liquid-liquid microextraction. J Chromatogr A. 2006;1116(1):1-9.

Rezaee M, Yamini Y, Faraji M. Evolution of dispersive liquid-liquid microextraction method. J Chromatogr A. 2010;1217:2342-57.

Sabermahani F, Taher M. Ali, Bahrami H. Separation and pre-concentration of trace amounts of gold from water samples prior to determination by flame atomic absorption spectrometry. Arabian J Chem. 2012. http://dx.doi.org/10. 1016/j.arabjc.2012.04.053In Press, Corrected Proof, Available online 9 May 2012.

Shamsipour M, Ramezani M. Selective determination of ultra trace amounts of gold by graphite furnace atomic absorption spectrometry after dispersive liquid-liquid microextraction. Talanta. 2008;75:294-300.

Tajic S, Taher MA. New method for microextraction of ultra-trace quantities of gold in real samples using ultrasound-assisted emulsification of solidified floating organic drops. Microchim Acta. 2011;173:249-57.

Tavakoli L, Yamini Y, Ebrahimzadeh H, Nezhadali A, Shariati S, Nourmohammadian F. Development of cloud point extraction for simultaneous extraction and determination of gold and palladium using ICPOES. J Hazard Mater. 2008;152:737-43.

Vasilyeva A, Yudelevich IG, Gindin LM, Lanbina TV, Shulaman RS, Kotlaversky IL, Andrievsky VN. Extractive concentration of platinum-group elements and their determination by atomic-absorption spectrophotometry. Talanta. 1975;22:749.

Yamini Y, Moradi M, Tahmaseb E. High-throughput quantification of palladium in water samples by ion pair based-surfactant assisted microextraction. Anal Chim Acta. 2012;728:26-30.

Yana $\mathrm{H}$, Wanga $\mathrm{H}$. Recent development and applications of dispersive liquidliquid microextraction. J Chromatogr A. 2013;1295:1-15.

Ye R, Beng Khoo S. Cathodic stripping voltammetric determination of ultratrace $\mathrm{Au}$ (III) at a bulk modified epoxy-graphite tube composite electrode in flow systems. Analyst. 1999;124:353-60.

Ye J, Liu S, Tina M, Li W, Hu B, Zhou W, Jia O. Preparation and characterization of magnetic nanoparticles for the on-line determination of gold, palladium, and platinum in mine samples based on flow injection micro-column preconcentration coupled with graphite furnace atomic absorption spectrometry. Talanta. 2014;118:231-7.

Zhang L, Zhenhua L, Zheng $H$, Xijun C. Solid phase extraction of gold(III) on attapulgite modified with triocarbohydrazide prior to its determination in environmental samples by ICP-OES. Spectrochim Acta A. 2011;79:1234-9. 